Eskişehir Osmangazi Üniversitesi iiBF Dergisi

Nisan 2020, C. 15, S. 1, $249-266$.

Başvuru : :11.01.2019

Kabul : 20.01.2020

\title{
Yüksek ve Düşük Teknolojili Sektörlerde Piyasaya Girişin Belirleyicileri
}

Gülçin Gürel Günal ${ }^{1}$

Ertuğrul Deliktaş²

Yüksek ve Düşük Teknolojili Sektörlerde Piyasaya Girişin Belirleyicileri

Öz

Bu çalışmada, sürdürülebilir bir büyümenin en önemli unsurlarından birisi olan imalat sanayii, piyasa yapısı analizi çerçevesinde piyasaya giriş modeli oluşturularak incelenmektedir. Bu çerçevede kullanılan modellerde düşük teknolojili ve yüksek teknolojili imalat sanayii sektörleri, 2003-2015 yılları için lojistik regresyon modeli kullanılarak analiz edilmektedir. Analiz sonuçlarına göre piyasaya girişte, farklı teknoloji düzeyindeki firmalar farklı değişkenlerden etkilenmektedir. Diğer taraftan makroekonomik gelişmelerin, firmaların sektöre giriş kararında firma ve piyasa özelindeki gelişmelerden daha etkili olduğu da görülmektedir. Özellikle teknoloji yoğun firmaların makroekonomik gelişmelerden çok fazla etkilendiği dikkat çekmektedir. Çalışmanın, firmaların piyasaya giriş kararlarının mikro ve makro düzeyde nasıl değiştiğini görebilmek adına politika yapıcılar için önemli olduğu düşünülmektedir.

Anahtar Kelimeler: Endüstriyel Organizasyon, İmalat Sanayii, Piyasa Yapısı, Piyasaya Giriş, Düşük-Yüksek Teknoloji

\section{Giriş}

İktisadi büyüme, uzun yıllardır temel tartışma konusu olmaya devam etmekte olup, büyüme ile ilgili çok sayıda yaklaşım geliştirilmiştir. Bu çerçevede, Post Keynesyen yaklaşımı temsil eden Kaldor (1966), büyümenin temel gücünün sanayi sektörü olduğunu vurgulamış, sanayi sektöründeki üretim artışları sonucunda büyümenin gerçekleşeceğini söylemiştir. Bu nedenle sanayi sektörü, iktisadi büyümede temel bir güç olarak kabul edilmiştir (McCombie, 1982).

Sanayi kavramı, 1774 yılında İngiltere'de başlayan sanayi devrimi ile ortaya çıkmıştır. Sanayi devrimi, başta Avrupa ülkeleri olmak üzere tüm dünyada sanayi sektörünün hızla gelişmesine neden olmuştur (Kozal ve Barbaros, 2019). Türkiye için de bu gelişmelerin etkisi 1800'lü yılların başında görülmeye başlamış ve bu kapsamda az sayıda da olsa sanayi kuruluşunun faaliyet göstermeye başladığı görülmüştür (Doğan, 2013). Cumhuriyet yıllarında ise sanayi sektörünün önemi daha fazla vurgulanmıştır. Bu tarihten itibaren İzmir íktisat Kongresi ile birlikte sanayi

\footnotetext{
1 Arş. Gör. Dr., Ege Üniversitesi iiBF, İktisat Bölümü. gulcin.gurel@ege.edu.tr. Yazar ORCID bilgisi: https://orcid.org/0000-0003-4780-4420

2 Prof. Dr., Ege Üniversitesi IiBF, İktisat Bölümü. ertugrul.deliktas@ege.edu.tr. Yazar ORCID bilgisi: https://orcid.org/0000-0003-1999-8176
} 
sektörü odaklı çalışmalara başlanmıştır. Ayrıca devlet destekli özel sektör üretimine önem verilmiş ve Türkiye'de ithal ikameci politikalar hâkim olmuştur. 1960 yılından sonra ise planlı dönem başlamış, sanayiye dayalı büyüme ülkenin temel politikası haline gelmiştir. 1963 yılından itibaren oluşturulmuş tüm kalkınma planlarında sanayi sektörünün önemi vurgulanmıştır. İlaveten, 1980 yılında ihracata dayalı büyümeye geçilmesi, küreselleşmenin yaşanması ve finansal serbestleşmenin başlaması ile sanayi sektörü daha da önemli hale gelmiş, üretim düzeyi her geçen gün daha da artmıştır. 1990 yılından sonra, sanayi sektörü ile ilgili üç önemli dönüm noktası yaşanmıştır. Bunlardan ilki 2001 krizi ve diğeri de 2008'de başlayan ve 2009 yılında etkileri devam eden küresel finans krizidir. Çünkü 2001 yılında bankacılık sektörü özelinde yaşanmış olan ulusal kriz başta olmak üzere, 2008 yılında yaşanmış küresel finans kriz sonucunda sanayi sektörü üretim değerleri olumsuz etkilenmiştir. Diğer taraftan 2011 yılında Almanya'da ortaya çıkmış olan sanayi 4.0 kavramı da sanayi sektörüne farklı bir anlam katmış olan bir diğer önemli noktadır. Sanayi 4.0 ile sanayi sektöründe teknoloji kavramı önem kazanmış, teknoloji yoğunluklarına göre sektörler değerlendirilmeye başlanmış ve teknoloji yoğun sektörler ön plana çıkmıştır.

Bununla birlikte, sanayi sektörü içerisinde gerek üretime gerekse de istihdama olan katkısı ile en önemli alt sektörün imalat sanayii olduğu bilinmektedir (Koç vd., 2016). Tüm bu nedenlerde dolayı imalat sanayinin etkin çalışması ve bunun içinde etkin politikaların üretilmesi çok önemlidir. Etkin politikalar için de piyasa analizlerinin doğru olarak yapılması gerekmektedir. Bu çerçevede en önemli analiz, piyasa yapısı analizleridir. Bu sayede piyasanın rekabet düzeyi ve rekabet gücü tespit edilebilecek, etkin bir piyasa için nelerin yapılması gerektiği ortaya koyulabilecektir. Rekabet analizlerinde ise en önemli konulardan biri piyasaya giriş ve piyasadan çıkışlardır. Bu analizlerle gerek sayı bakımından gerekse de üretim değeri bakımından, piyasa içerisinde gerçekleşebilecek büyük değişimler incelenebilmektedir.

Sonuç olarak, Türkiye'de 1990 yılından sonra önemi daha da artmış olan sanayi sektörü, 2001 krizi ile büyük bir gerileme yaşamış, 2003 yılından itibaren ise toparlanmaya başlamıştır. Bu nedenle Türkiye'de sanayi sektörü 2003 yılı ile birlikte yeni bir döneme girmiştir. Bu yeni dönemde, piyasa yapısı analizleri kapsamında gözden kaçırılmaması gereken temel eğilimler Grafik 1-3'te verilmiştir. Her bir durum hem düşük teknolojili hem de yüksek teknolojili sektörler için ayrı ayrı incelenmiştir. Bu sayede, özellikle 2010 sonrası için sanayi 4.0 çerçevesinde bir değişim olup olmadığı da görülebilmiştir.

Grafik 1, 2003 yılından itibaren teknoloji yoğunluklarına göre sınıflandırılmış imalat sanayii üretim değerlerinde yaşanan değişimi göstermektedir. Grafikte de görüldüğü gibi, düşük teknolojili imalat sanayisinde üretimde yaşanan değişim negatif bir eğilime sahipken, yüksek teknolojili imalat sanayisinde pozitif bir eğilime sahiptir. 2003-2015 yılları arasında ise üretimde genel olarak pozitif artış oranları olmakla birlikte, 2009 yılında üretimde daralma yaşanmaktadır. Bu durum, 2008 krizinin 2009 yılında üretim değerleri üzerinden negatif bir etki göstermiş olduğunu ortaya koymaktadır. Bununla birlikte, takip edilen yıllarda genel olarak düşük oranlarla da olsa üretimde görülen artışların, teknoloji sınıflaması fark etmeksizin yıllar boyunca istikrarlı bir artış trendine girememiş olduğu görülmektedir. Çünkü bazı yıllarda yüksek bazı yıllarda düşük ve hatta bazı yıllarda negatif değişimler üretimde yaşanmaktadır. İlaveten, yüksek teknolojili sektörlerde 2012 yılından sonra, 2012 yılından öncesine göre üretimde daha yüksek oranlarda artışların yaşandığı görülmektedir. 
Grafik 1: Türk Imalat Sanayi'nde Teknoloji Düzeylerine Göre Üretimde Görülen Değişimler

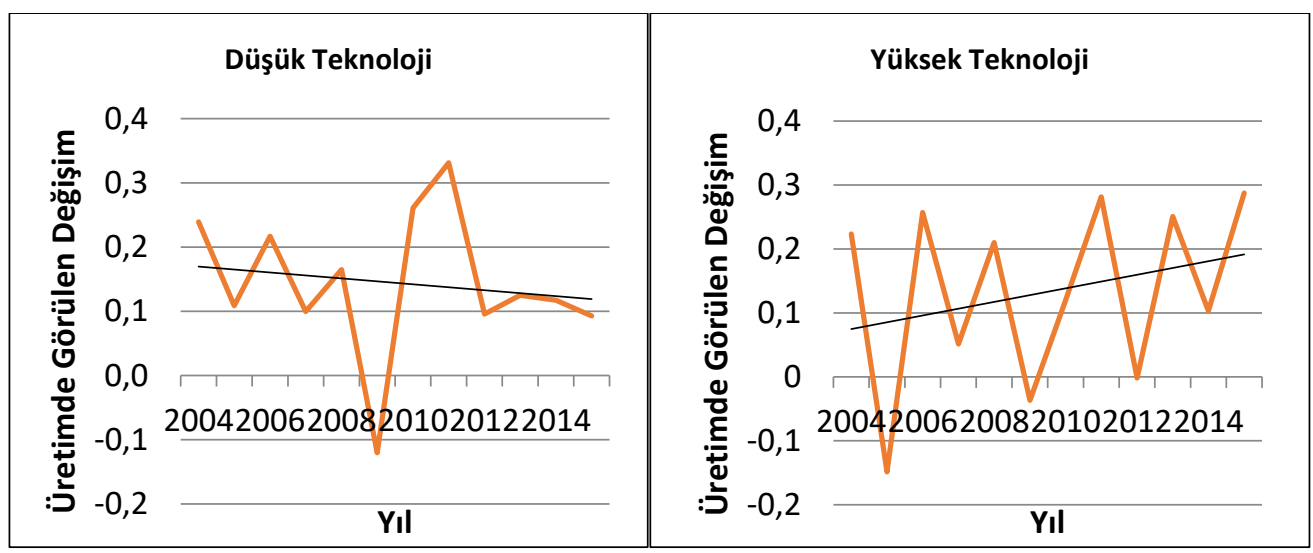

Kaynak: TÜiK verileri kullanılarak yazarlar tarafından oluşturulmuştur.

Teknoloji düzeylerine göre katma değerde meydana gelen değişimler de Grafik 2' de görülmektedir. Düşük teknolojili imalat sanayisinde, üretimde azalma trendi görülmesine rağmen, katma değerde artış trendine rastlanılmaktadır. Bu durum, daha çok emek yoğun sektörleri içeren düşük teknolojili sektörlerde, emek verimliliğinin özellikle 2012 yılından sonra olmak üzere artış eğiliminde olduğunu göstermektedir. Diğer taraftan yüksek teknolojili imalat sanayisindeki katma değerde, üretimle uyumlu olarak aynı oranlarda artış görülmektedir. Bununla birlikte, katma değerde de yıllar boyunca süren istikrarsız bir yapı karşımıza çıkmaktadır.

Grafik 2: Türk Imalat Sanayi'nde Teknoloji Düzeylerine Göre Katma Değerde Görülen Değişimler

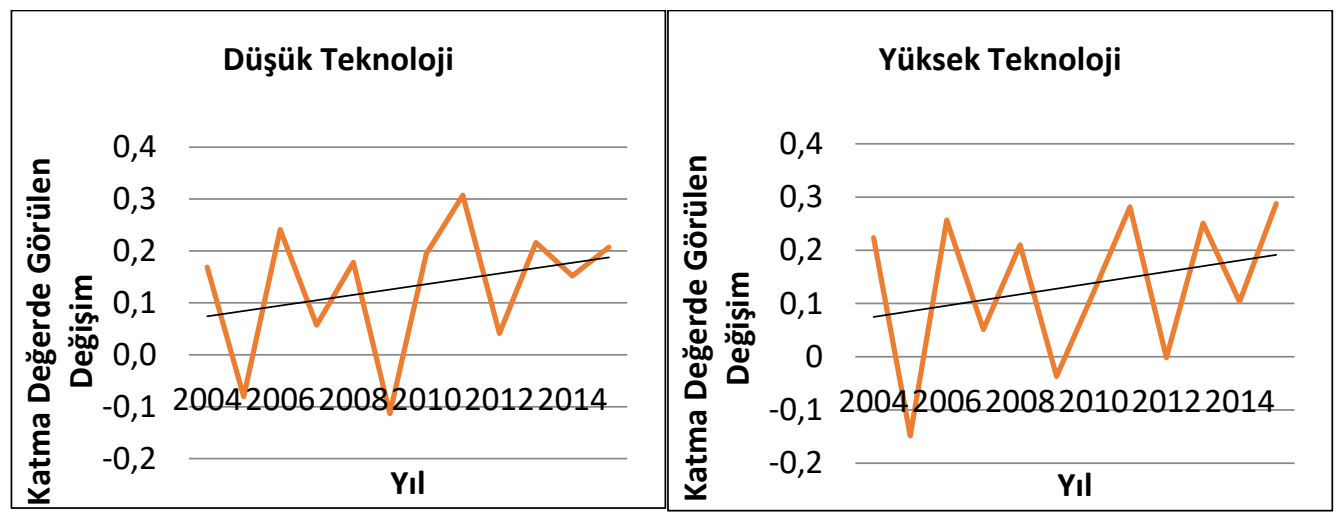

Kaynak: TÜiK verileri kullanılarak yazarlar tarafından oluşturulmuştur.

Üretimde ve katma değerde meydana gelen değişimlerin yanında bir diğer önemli analiz de, firmaların imalat sanayisine giriş motivasyonlarını ortaya koymaktır. Toplam üretim ve toplam katma değerde meydana gelen artışlar sonucunda, Türk İmalat Sanayi'ndeki işyeri sayısının da giderek artan oranlarda yükselmesi beklenmektedir. Bununla birlikte Grafik 3'te görülen, iş yeri sayısı bakımından imalat sanayisi genelinde giderek azalan oranlarda artış ve hatta azalış yaşanmasıdır. Bu durum, imalat sanayisine yönelik ilginin düştüğünü göstermektedir. 2009 yılından sonra, düşük teknolojili imalat sanayisinde işyeri sayısının azaldığı, 2012 yılından sonra ise iş yeri 
sayısında çok düşük düzeyde artışların yaşandığı görülmektedir. Benzer durum yüksek teknolojili imalat sanayisinde de yaşanmaktadır. Bu durum, Sanayi 4.0’ın Türk imalat sanayisi için henüz bir teşvik oluşturmamış olduğunu ortaya koymaktadır.

Grafik 3: Türk Imalat Sanayi'nde Teknoloji Düzeylerine Göre Işyeri Sayısında Görülen Değişimler

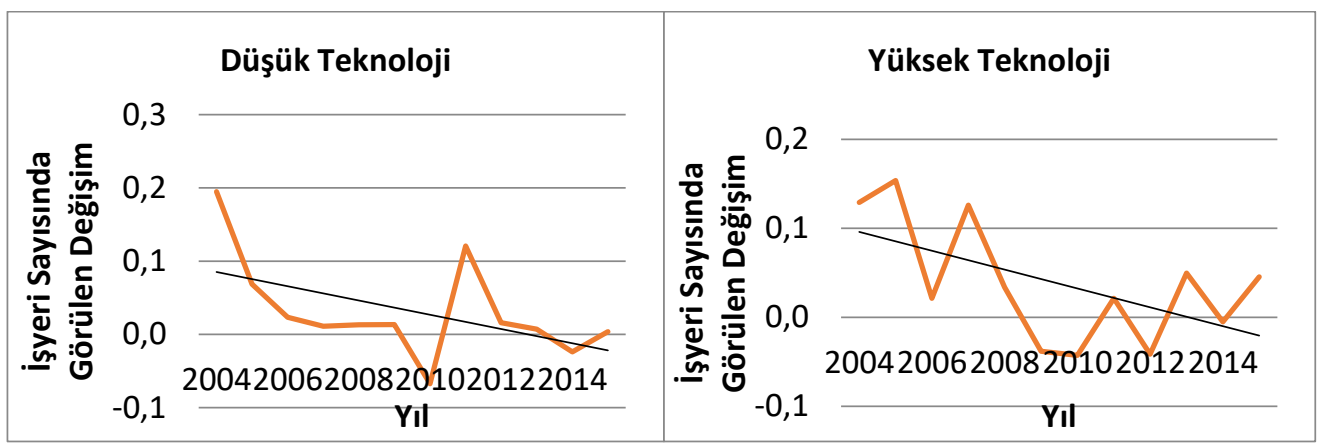

Kaynak: TÜiK verileri kullanılarak yazarlar tarafından oluşturulmuştur.

Yukarıda verilmiş üç grafik özetle, düşük teknolojili imalat sanayisinde görülen üretimde değişimlerin azalma eğilimine girmiş olmasına karşılık katma değerde yaşanan değişimlerin yükseliş eğiliminde olduğunu ve bununla birlikte sektör içerisinde yeni işyeri açmanın çok tercih edilmediğini ortaya koymaktadır. Bu durum, düşük teknolojili imalat sanayisinde verimliliğin artış eğiliminde olduğu hakkında fikir oluşturmaktadır. Buna rağmen sektör, yeni firmalar için çekicilik sağlamamaktadır. Diğer taraftan yüksek teknolojili imalat sanayisinde hem üretim hem de katma değer de değişim artış eğilimine sahiptir. Ancak yüksek teknolojili imalat sanayisinde de yeni firma açma eğilimi azalmaktadır. Bu gelişmeler, imalat sanayisine yönelik ilginin azaldığını göstermektedir.

Sonuç olarak, 1990 yılından sonra büyüme kavramının ve imalat sanayii sektörünün önemi daha da vurgulanmış olmasına rağmen gerek üretimde gerekse de katma değer yaratımında imalat sanayii istenilen düzeye gelememiştir. Bununla birlikte, firmaların imalat sanayisine giriş kararlarında da azalma görülmüştür. Bu durum imalat sanayisinin detaylı analizini gerekli kılmaktadır. Çünkü düşük oranlarda yaşanan üretim ve katma değer artışları ile birlikte imalat sanayisinin giderek ilgi çekiciliğinin azalması rekabet politikaları bakımından incelenmesi gereken bir konu olmaktadır. Bu çerçevede piyasaya girişin temel motivasyonlarının ortaya çıkarılması, iktisadi büyüme için uygun politikaların oluşturulması adına önemli bir adım olarak görülmektedir.

\section{Piyasaya Girişin Belirleyicileri}

Endüstriyel organizasyon teorileri altında firma ve piyasa davranışları, kısa ve uzun dönemde farklılık göstermektedir. Kısa dönemde fiyatlar üzerinden işleyen firma ve piyasa yapısı ${ }^{3}$, uzun dönemde birçok farklı etmenden etkilenebilmektedir. Bu çerçevede en önemli etmenlerden biri de, firmaların piyasa giriş kararı almaları olarak karşımıza çıkmaktadır. Çünkü piyasaya yeni gi-

\footnotetext{
${ }^{3}$ Yeni bir firmanın piyasaya girmesi sonucunda firma sayısı artacaktır. Bu durum rekabeti arttıracak ve bunun sonucunda fiyatlar genel düzeyinde düşüşler beklenecektir. Düşen fiyatlar, daha yüksek maliyetlerle çalışan firmaları daha düşük maliyetle üretim yapmaya yöneltecektir. Bu durum da tüketicilere düşük fiyat sağlayacak, üretici de kaynakları verimli kullanacaktır (Çetin, 2010).
} 
ren bir firma, sektörün dinamiklerini değiştirebilmektedir. Bu çerçevede yeni bir firmanın piyasaya girişi sonucunda, piyasadaki firma sayısı artmakta, yeni ürünler ve yeni teknolojiler piyasaya ulaşabilmektedir (Öztürk ve Karabıyık, 2007). Ayrıca değişen bilanço değerleri sonucunda piyasa ölçeği değişebilmektedir. Özetle gerek değişen firma sayıları gerek ürün çeşitliliği gerekse de bilanço değerlerinin değişmesi sonucunda piyasanın rekabet yapısı farklılaşabilmektedir (Şahin, 2011). Diğer bir ifadeyle, tüm bu değişimlere neden olmasından dolayı piyasaya giriş, piyasa yapısının etkileyebilmektedir. Bu nedenle piyasa yapısının belirlenmesinde piyasaya giriş kararları önemli rol oynamaktadır.

Bununla birlikte, yaşanan bazı gelişmeler sonucunda bazı dönemlerde piyasaya girişler artmakta, bazı dönemler de azalmaktadır. Bu duruma; piyasa talebi, maliyetlerde görülen değişimler, piyasadaki yoğunlaşma düzeyi, dış ticaret potansiyeli, ulusal ve uluslararası krizler, devletin ve özel sektörün teşvik politikalarının değişimi, hızla gelişen teknolojiye ayak uyduramamak gibi gelişmeler sebep olmaktadır. Diğer taraftan 1990 yılından sonra bilgi toplumuna geçiş ve özellikle 2011 yılından sonra da sanayi 4.0 kavramı ile teknoloji ve teknolojiye dayalı sektörel gelişimler, piyasaya giriş kararlarında mutlaka dikkate alınması gerekli faktörler olarak karşımıza çıkmaktadır (Arıkan, 2015). Sonuç olarak piyasaya girişin; piyasa ve makro iktisadi gelişmeler özelindeki göstergelerden etkilendiği görülmektedir. Bu nedenle, piyasa yapısı analizleri yapılırken piyasaya girişin belirleyicileri, piyasa ve makro iktisadi gelişmeler dikkate alınarak mutlaka değerlendirilmelidir. Çünkü bu değerlendirme ile piyasaya girişi etkileyen değişkenler elde edilebilecek ve buna bağlı olarak etkin bir piyasa yapısı için politika yapıcılar tarafından uygulanması gereken politikalar belirlenebilecektir.

Piyasaya giriş, doğrudan veya birleşmeler sonucunda olmak üzere iki türde meydana gelmektedir. Piyasaya doğrudan giriş, yeni bir firmanın (daha önce piyasada faaliyet göstermeyen) piyasada faaliyetine başlamasıdır. Birleşme ise; bir firmanın, bir veya daha fazla firma ile tüm bilanço değerlerini ortak bir yapıda toplaması ve bu yapının hukuken var olan yeni bir firma tarafından idare edilmesidir (Türk Ticaret Kanunu, 2011, Mad. 146). Birleşme de bir firmanın başka bir firmayı devralması veya iki veya daha çok sayıda firmanın tek bir yeni yapı altında toplanması şeklinde olmak üzere iki şekilde gerçekleşebilmektedir (Yücebaş, 2005).

Endüstriyel organizasyon teorisi altında, piyasaya giriş davranışlarını inceleyen çalışmalar, Bain'e (1951) dayanmaktadır. Bain (1951), piyasaya giriş faaliyetlerinde çekici (teşvikler) ve itici (engeller) güçler olduğunu belirtmekte; ölçek ekonomilerini, ürün farklılaştırmasını ve mevcut firmaların maliyet avantajına sahip olmalarını, en temel piyasaya giriş engelleri olarak tanımlamaktadır. Ilaveten, piyasanın karlılık düzeyi de teşvik edici bir unsur olarak belirtilmektedir. Bain'in (1951) çalışmasından sonra, farklı sektörler için çeşitli ampirik çalışmaların, genel olarak 1970'li yıllardan sonra yapılmış olduğu görülmektedir. Yapılan bu çalışmalarda piyasa giriş kararlarının belirleyicileri genel olarak; firma maliyetleri, karlılık, verimlilik, ölçek, yoğunlaşma oranları araştırma ve geliştirme destekleri, dış ticaret potansiyeli, teknolojik gelişmeler ve istikrar değişkenlerine odaklanmaktadır. Bununla birlikte ülkelerin ve sektörlerin sahip oldukları özelliklere göre bu belirleyiciler değişebilmektedir. Bu nedenle ülkelerin ve sektörlerin sahip oldukları bu özelliklerin dikkate alındığı çeşitli çalışmalar literatürde bulunmaktadır. Yapılan çaIışmalar genel olarak sanayi sektörü ve bankacılık sektörü üzerine odaklanmaktadır. Temel olarak, Amel ve Liang (1997), Berger vd. (1999), Avery vd. (1999), Adams ve Amel (2016) tarafından ABD, Gobbi ve Lotti (2004) tarafından İtalya ve Pagnini vd. (2017) tarafından Avusturya bankacılık sektörü için piyasaya giriş ile ilgili analizlerin gerçekleştiği görülmektedir. Sanayi sektörüne yönelik olan çalışmaların da genel olarak imalat sanayii odaklı olduğu dikkat çekmektedir. Bu 
kapsamda öne çıkan çalışmalar ise, Orr (1974) Kanada, Austin ve Rosenbaum (1990) ve Rosenbaum (1993) ABD, Roh (2018) hem Kanada hem de ABD, Genchev (2015) Avustralya, Cala (2018) Arjantin için yapılmış piyasaya giriş analizlerine dayanmaktadır. ABD için 1970-1990 yılları arasında genel olarak piyasanın büyüme derecesi, karlılık, reklam harcamaları gibi piyasa özelindeki değişkenlerin; 2000'li yıllardan itibaren ise başta iktisadi büyüme ve işsizlik olmak üzere makro iktisadi değişkenlerin piyasaya giriş konusunda daha çekici etki yarattığı dikkat çekmektedir. Bununla birlikte Arjantin sanayi sektörü için teknolojik farklılıkların dikkate alındığı çalışmada, piyasaya giriş motivasyonunda teknolojik farklılıkların etkili olduğu vurgulanmaktadir.

Türkiye özelinde yapılmış çalışmaların ise daha dar kapsamda kaldığı ve genel olarak imalat sanayii özelinde yapıldığı göze çarpmaktadır. Bununla birlikte yapılan çalışmalar 1980-2001 yılları arasındaki döneme odaklanmaktadır. Kaya ve Üçdoğruk (2002), Günalp ve Cilasun (2006), Turanlı ve Kılıç (2009), Öztürk ve Kılıç (2012), Öztürk ve Dietrich (2012) ve İzgi ve Dineri (2014) tarafından Türkiye için yapılmış çalışmalar, piyasaya girişte temel belirleyicilerin karlılık, yoğunlaşma, üretim, emek verimliliği, personel maliyeti, reklam gibi piyasa özelindeki değişkenlere dayandığını ortaya koymakla birlikte, Turanlı ve Kılıç (2009) ve Öztürk ve Kılıç (2012) piyasaya giriş kararında enflasyon ve dış ticaret gibi makro iktisadi gelişmelerin de etkili olduğunu ortaya koymaktadır. Yapılan çalışmalar, 2001 yıından sonraki gelişmeler doğrultusunda Türk imalat sanayiine giriş için belirleyicilerin analiz edilmediğini göstermektedir. Bununla birlikte piyasaya giriş analizlerinde teknolojik farklılıklara sahip sektörlerde tek ve ortak belirleyicilerin olamayacağı ortadadır. Ancak görüldüğü gibi literatürde yapılmış çalışmalar bu ayrımı da dikkate almamaktadır. Bu nedenle, çalışmada yüksek ve düşük teknolojili sektör ayrımına odaklanılmakta ve yüksek ve düşük teknolojili sektörlerin her biri için ayrı olarak piyasaya girişin temel belirleyicileri 2003 yılından sonrası için ortaya koyulmaktadır.

\subsection{Veri Seti}

Çalışmada, 2003-2015 yılları için Türk imalat sanayiinde piyasaya girişin belirleyicileri, düşük ve yüksek teknolojili sektörler ayrımına odaklanarak analiz edilmiştir. Analizde NACE 2 sınıflaması altında on yedisi düşük teknolojili ve yedisi yüksek teknolojili sektör olmak üzere imalat sanayiinin 24 alt sektörü incelenmiştir.

Tablo 1'de de görüldüğü gibi çok sayıda alternatif değişkenden yararlanılmıştır. Bu çerçevede, bağımlı değişken olan piyasaya giriş için, analizin yapıldığı yıl içerisinde toplam firma sayısında pozitif değişimin meydana gelmesi durumuna " 1 " ve negatif bir değişimin yaşanması durumuna " 0 " değeri verilerek veri seti oluşturulmuştur.

Analiz kapsamında tercih edilen bağımsız değişkenler ise piyasa özelliklerini ve makro iktisadi koşulları yansıtan değişkenler olmak üzere iki gruba ayrılmıştır. Piyasa özellikleri çerçevesinde işgücü başta olmak üzere girdi maliyetleri, karlılık, verimlilik, piyasanın ölçeği, piyasada görülen yoğunlaşma, piyasanın üretim bakımından büyüme oranı dikkate alınmıştır. Diğer taraftan makro iktisadi gelişmelerin etkisini göstermek için nüfus, özel sektör ve devlet ar-ge harcamaları, enflasyon, iktisadi özgürlük endeksi, krizler, dış ticaret hacmi, doğrudan yabancı yatırımlar ve trend gibi temel değişkenler modele dahil edilmiştir.

Analizde girdi maliyetleri altında işgücü maliyetleri için toplam çalışan maliyetleri (w1) ve üretimde kullanılan ara girdi maliyetleri olarak toplam mal ve hizmet alımı (w2) kullanılmıştır. Karlılık ise faktör fiyatları ile katma değerden, çalışanlara yapılan ödemeler çıkarıldıktan sonra 
elde edilen değerin ciro değerine bölünmesi ile hesaplanmıştır. Verimlilik olarak çalışanların verimliliği dikkat alınmış ve toplam üretimin toplam çalışan sayısına bölünmesi ile elde edilen değerler modelde kullanılmıştır. Piyasa ölçeği için literatürde kullanılan logaritma alma işlemi yapılmış ve bu kapsamda toplam üretimin logaritması elde edilmiştir. Piyasanın yoğunlaşma düzeyini göstermek için $\mathrm{HHI}$ ve $\mathrm{Cr}_{3}$ değerleri; büyüme potansiyelini göstermek için de yıllık üretim değerinde meydana gelen değişimler kullanılmıştır. Diğer taraftan toplam talep göstergesi olarak nüfus artış oranı tercih edilmiştir. Çalışmada, araştırma ve geliştirme desteklerinin etkisini göstermek amacıyla özel sektörün ve devletin imalat sanayisine yatırım yoluyla yapmış oldukları araştırma ve geliştirme harcamaları kullanılmıştır. Ayrıca imalat sanayisine yapılmış olan doğrudan yabancı yatırımlar da modele eklenmiştir. Diğer taraftan istikrar göstergesi olarak enflasyon tercih edilmiş, 2008 krizinin imalat sanayisine etkisi görmek amacıyla da kriz yılı için kukla değişken oluşturulmuştur. İmalat sanayisi için önemli olan ticaret hacmi değişkeni de ithalat ve ihracat değerlerinin toplam üretim içerisindeki payı elde edilerek modele dahil edilmiştir.

Illaveten, hukuki yapının göstergesi olarak; mülkiyet hakları, yargıda etkinlik, yönetimde bütünlük, ticari faaliyetlerde, finansal alanda ve yatırımda özgürlük, işgücünün özgür olması gibi alt endekslerden oluşan iktisadi özgürlük endeksi çalışmada kullanılmıştır. Teknolojik gelişmelerin etkisini görmek amacıyla trend değişkeni de modele eklenmiştir.

Tablo 1: Veri Seti Bilgileri

\begin{tabular}{|c|c|c|}
\hline Değişken Türü & Değişken Adı & Veri Özelliği \\
\hline Bağımlı Değişken & Y & $\begin{array}{c}\text { Firma sayısında görülen değişim } \\
\text { (kukla değişken) }\end{array}$ \\
\hline \multirow{8}{*}{$\begin{array}{c}\text { Bağımsız Değişkenler Firma ve Pi- } \\
\text { yasa Özelinde } \\
\text { (gecikmeli değerler) }\end{array}$} & $W_{1}$ & İşgücü Maliyetleri \\
\hline & $\mathbf{W}_{\mathbf{2}}$ & Toplam Mal ve Hizmet Alımı \\
\hline & Kar & (Katma Değer-Çalışanlara Yapılan \\
\hline & Verimbilik & 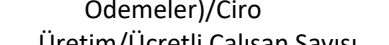 \\
\hline & Ölcek & Iog Tonlam Üretim \\
\hline & Yoॅ̆unlacma & HHIV $r_{r}$ \\
\hline & 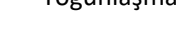 & nin ve Cls \\
\hline & Büyüme & $\begin{array}{c}\text { Piyasanın Büyümesi (Üretim De- } \\
\text { ğeri) }\end{array}$ \\
\hline \multirow{10}{*}{$\begin{array}{l}\text { Bağımsız Değişkenler } \\
\text { Makro Büyüklükler } \\
\text { (gecikmeli değerler) }\end{array}$} & Nüfus & Nüfus (miktar) \\
\hline & AR-GE1 & Özel Sektör Ar\&Ge Desteği \\
\hline & AR-GE2 & Kamu Sektörü Ar\&Ge Desteği \\
\hline & Enf & Enflasyon \\
\hline & İöe & İktisadi Özgürlük Endeksi \\
\hline & Kriz & 2008 Krizi \\
\hline & İth & İthalat/Üretim \\
\hline & İhr & İhracat/Üretim \\
\hline & Dyy & $\begin{array}{l}\text { İmalat Sanayii İçin Yapılan Doğru- } \\
\text { dan Yabancı Yatırımlar }\end{array}$ \\
\hline & $\mathrm{T}$ & Trend \\
\hline
\end{tabular}

Kaynak: Yazarlar tarafından oluşturulmuştur. 
Çalışmada kullanılan iktisadi özgürlük endeksi heritage (miras) resmi sitesinden; nüfus, doğrudan yabancı yatırımlar ve enflasyon verileri T.C. Cumhurbaşkanlığı Strateji ve Bütçe BaşkanIığı'ndan; diğer tüm değişkenler ise TÜik resmi sitesinden alınmıştır.

Tablo 1'de verilmiş değişkenler arasından modelde kullanılacak olan değişkenlerin belirlenmesi için öncelikle birim kök testleri ve ardından da bağımlı ve bağımsız değişkenler arasındaki ilişkilerin tespiti için nedensellik testleri yapılmıştır. Ayrıca değişkenler arası ilişkinin ortaya koyulabilmesi için korelasyon tablosu oluşturulmuştur. Tüm bu analizler sonucunda; işgücü maliyetleri, karlılık, verimlilik, yoğunlaşma piyasanın büyümesi, nüfus, enflasyon, doğrudan yabancı yatırımlar, kriz ve trend değişkeninin kullanılmasına karar verilmiştir. Bununla birlikte özel sektör ve devlet araştırma ve geliştirme harcamaları, ithalat ve ihracat değişkenlerinin kendi aralarında yüksek korelasyon ilişkisinin bulunmasından dolayı bu değişkenler ayrı ayrı modele eklenmiştir. Modelde oransal olmayan tüm değişkenlerin doğal logaritması alınmıştır.

Analiz kapsamında, her bir değişkenin bir yıl gecikmeli değeri kullanılmıştır. Çünkü firmalar bir önceki dönemi dikkate alarak kararlarını almakta ve bu çerçevede geleceğe yönelik strateji geliştirmektedirler.

\subsection{Yöntem ve Model}

Çalışmada lojistik regresyon modeli kullanılmaktadır. Bağımlı değişkenin kukla değişken ve bağımsız değişkenlerin de kesikli ve sürekli olduğu durumlarda panel veri modellerinden lojistik regresyon modeli daha etkin sonuçlar vermektedir. Bu modelde, bağımlı değişken, 1 veya 0 olmak üzere iki farklı değer almaktadır. Lojistik regresyon yöntemi bağımsız değişkenlerde meydana gelen değişimler sonucunda bağımlı değişkenin gerçekleşme olasılığını da ortaya koymaktadır (Akay, 2015). Bu olasılık odds oranı olarak tanımlanan olasılık oranı ile gösterilmektedir.

Lojistik regresyon analizinde modele dahil edilecek değişkenlerin seçimi çok önemlidir. Bu nedenle değişken seçiminde literatür ve önsel bilgiler kullanılarak temel değişkenler belirlenmektedir. Daha sonra da ileriye doğru seçim, geriye doğru seçim ve adım adım seçim yöntemlerinden birine karar verilmekte ve uygun değişkenler modelde bırakılmaktadır. Uygun olan değişken seçme yönteminin belirlenmesinden sonra hangi değişkenlerin uygun olduğuna ise log olabilirlik testi ile karar verilmektedir. Bu çerçevede, yeni bir değişkenin modele eklenmesi sonucunda Log Olabilirlik değerinde yüksek oranda bir değişim gerçekleşiyorsa, modele eklenen yeni değişkenin model için gerekli olduğu düşünülmektedir. (Öztürk, 2010). Ayrıca tahmin edilen modellerin uyum iyilik testlerinin de yapılması gerekmektedir.

Analiz çerçevesinde seçilmiş uygun modeller aşağıda verilen 5 denklemde gösterilmiştir.

Düşük ve Ileri Teknoloji Sektörler için Piyasaya Giriş:

$$
\begin{aligned}
& Y_{i t}=\beta_{0}+\beta_{1} W_{i t}+\beta_{2} \text { Kar }_{i t}+\beta_{3} \text { Verimlilik }_{i t}+\beta_{4} \text { Yoğunlaşma }_{i t}+\beta_{5} \text { Büyüme } i t+ \\
& \beta_{6} N \text { üfus }{ }_{i t}+\beta_{7} E n f_{i t}+\beta_{8} \dot{I} e_{i t}+\beta_{9} \text { Kriz }_{i t}+\beta_{10} D y y_{i t}+t+\varepsilon_{i t}
\end{aligned}
$$

$$
\begin{array}{r}
Y_{i t}=\beta_{0}+\beta_{1} W_{i t}+\beta_{2} \text { Kar }_{i t}+\beta_{3} \text { Verimlilik }_{i t}+\beta_{4} \text { Yoğunlaşma }_{i t}+\beta_{5} \text { Büyüme }_{i t}+ \\
\beta_{6} N \text { üfus } \text { sit }_{i t}+\beta_{7} \text { Arge }_{i t}+\beta_{8} \text { Enf }_{i t}+\beta_{9} \dot{I} \text { Ï } e_{i t}+\beta_{10} \text { Kriz }_{i t}+\beta_{11} D y y_{i t}+t+\varepsilon_{i t}
\end{array}
$$




$$
\begin{aligned}
Y_{i t} & =\beta_{0}+\beta_{1} W_{i t}+\beta_{2} \text { Kar }_{i t}+\beta_{3} \text { Verimlilik }_{i t}+\beta_{4} \text { Yoğunlaşma }_{i t}+\beta_{5} \text { Büyüme }_{i t}+ \\
\beta_{6} N \text { üfus } & +\beta_{7} \text { Arge }_{i t}+\beta_{8} \text { Enf }_{i t}+\beta_{9} \dot{I} \text { Ï } e_{i t}+\beta_{10} \text { Kriz }_{i t}+\beta_{11} D y y_{i t}+t+\varepsilon_{i t}
\end{aligned}
$$

$$
\begin{aligned}
Y_{i t} & =\beta_{0}+\beta_{1} W_{i t}+\beta_{2} \text { Kar }_{i t}+\beta_{3} \text { Verimlilik }_{i t}+\beta_{4} \text { Yoğunlaşma }_{i t}+\beta_{5} \text { Büyüme }_{i t}+ \\
\beta_{6} N \text { üfus } & +\beta_{7} \dot{\mathrm{I}} t h_{i t}+\beta_{8} \text { Enf }_{i t}+\beta_{9} \dot{\mathrm{I}} e_{i t}+\beta_{10} \text { Kriz }_{i t}+\beta_{11} D y y_{i t}+t+\varepsilon_{i t}
\end{aligned}
$$

$$
\begin{aligned}
Y_{i t} & =\beta_{0}+\beta_{1} W_{i t}+\beta_{2} \text { Kar }_{i t}+\beta_{3} \text { Verimlilik }_{i t}+\beta_{4} \text { Yoğunlaşma }_{i t}+\beta_{5} \text { Büyüme }_{i t}+ \\
\beta_{6} N \text { üfus } & +\beta_{7} \text { İ } h r_{i t}+\beta_{8} \text { Enf }_{i t}+\beta_{9} \mathrm{I} \text { Ïo } e_{i t}+\beta_{10} \text { Kriz }_{i t}+\beta_{11} D y y_{i t}+t+\varepsilon_{i t}
\end{aligned}
$$

Yukarıda verilen denklemlerde, Y piyasaya girişi temsil eden kukla değişkeni, w1 işgücü maliyetlerini, Kar firmaların elde ettiği karı, Verimlilik işgücü verimliliğini, Yoğunlaşma piyasada üretim bakımından en büyük üç firmanın yoğunlaşma düzeyini, Nüfus toplam nüfusta meydana gelen değişimi, Arge1 özel sektörün imalat sanayisine yapmış olduğu araştırma ve geliştirme harcamalarını, Arge2, devletin imalat sanayisine yapmış olduğu araştırma ve geliştirme harcamalarını, ihr imalat sanayisi özelinde gerçekleşen ihracat değerinin toplam imalat sanayii üretimi içerisindeki payını, ith imalat sanayisi özelinde gerçekleşen ithalat değerinin toplam imalat sanayii üretimi içerisindeki payını, Enf yıllık enflasyon oranını, löe iktisadi özgürlük endeksini, Kriz küresel finans krizini, Dyy imalat sanayisine yönelik gerçekleşen doğrudan yabancı yatırımları ve $t$ teknolojik gelişmeleri temsil etmektedir. Değişkenlere ait betimsel istatistikleri gösteren tablolar ise ek 1 ve ek 2'de verilmiştir.

\subsection{Analiz Sonuçları}

Türk imalat sanayisi için piyasaya girişin belirleyicileri, düşük teknolojili ve yüksek teknolojili imalat sanayii ayrımı çerçevesinde 2003-2015 yılları için analiz edilmektedir. Analiz çerçevesinde kullanılan lojistik regresyon modelleri ile de her bir değişken için katsayılar ve odds değerleri hesaplanmaktadır. Çalışma kapsamında katsayıların ve odds değerlerinin birlikte verildiği tek bir tablo kullanılmaktadır. Tablo 2 ve Tablo 3'te verildiği gibi parantez içindeki değerler katsayıların işaretini, değişken değerleri ise odds değerini temsil etmektedir. Söz konusu değişkenin katsayı işareti, firmaların piyasaya giriş kararının hangi yönde etkilendiğini ortaya koymaktadır. Bununla birlikte söz konusu değişkenin odds değeri ise, firma kararının hangi düzeyde (güçte) etkilendiğini göstermektedir.

Tablo 2 ve Tablo 3'te görüldüğü gibi analiz kapsamında hem düşük teknolojili hem de yüksek teknolojili imalat sanayisi için 5 alternatif modele ait sonuçlar elde edilmiştir. Bu modellerin oluşturulmasında ise adım adım yöntemi kullanıımıştır. Her bir değişken sırasıyla modele eklenmiş, Log Olabilirlik değerini çok etkileyerek modele katkı sağlayan değişkenler modelde bırakılmış, Log Olabilirlik değerini çok az değiştirerek katkı sağlamayan değişkenler ise modelden çıkarılmıştır. Her iki tabloda da görüldüğü gibi model 2, model 3, model 4 ve model 5 'in log likelihood değerleri model 1'den çok yüksek çıkmış, bu dört modelin değerleri ise birbirine çok yakın değerde elde edilmiş ve bu nedenle çalışmada bu dört model birlikte yorumlanmıştır. Çünkü 
bu dört model neredeyse aynı olmakla birlikte her bir modelde sadece tek değişken değiştirilmiştir. Model 2'de özel özel sektör ar-ge desteği, model 3'te kamu sektörü ar-ge desteği, model 4'te ihracat etkisi, model 5'te de ithalat etkisi ayrı ayrı modele dahil edilmiştir.

Bağımlı değişkenin firmalaşma olduğu 2003-2015 yılları için yapılan analizlerde, düşük teknolojili imalat sanayisinde piyasaya girişin temel belirleyicileri olarak karşımıza verimlilik, yoğunlaşma, iktisadi büyüme, iktisadi özgürlük endeksi, enflasyon, özel sektör ve kamu sektörü araştırma ve geliştirme harcamaları çıkmaktadır. Bununla birlikte yüksek teknolojili imalat sanayisinde piyasaya girişin belirleyicileri olarak personel maliyeti, yoğunlaşma, nüfus, enflasyon, özel sektör ve kamu sektörü araştırma ve geliştirme harcamaları, doğrudan yabancı yatırımlar, küresel finans krizi ve dış ticaret işlemleri öne çıkmaktadır.

Tablo 2: Düşük Teknolojili Imalat Sanayisinde Piyasaya Girişin Belirleyicileri

\begin{tabular}{|c|c|c|c|c|c|}
\hline \multirow[b]{2}{*}{$\begin{array}{c}\text { Değişkenler için } \\
\text { gecikmeli değerler }\end{array}$} & \multicolumn{5}{|c|}{ Lojistik Regresyon Sonuçları-Bağımlı Değişken: Firmalaşma (kukla değişken) } \\
\hline & Model 1 & Model 2 & Model 3 & Model 4 & Model 5 \\
\hline \multicolumn{6}{|c|}{ Firma ve Sektör Özelinde Değişkenler } \\
\hline $\mathbf{W}_{1}$ & $(+) 1.23$ & $(+) 1.28$ & $(+) 1.28$ & $(+) 1.12$ & $(+) 1.12$ \\
\hline Kar & $(+) 0.56$ & $(+) 0.59$ & $(+) 0.60$ & $(+) 0.43$ & $(+) 0.45$ \\
\hline Verimlilik & $(+) 1.04 * *$ & $(+) 1.05^{* *}$ & $(+) 1.05 * *$ & $(+) 1.06 * *$ & $(+) 1.07 * *$ \\
\hline Yoğunlaşma & $(-) 1.42 * * *$ & $(-) 1.39 * * *$ & $(-) 1.42 * * *$ & $(-) 1.37 * * *$ & $(-) 1.37 * * *$ \\
\hline Büyüme & $(+) 0.21^{*}$ & $(+) 0.17^{*}$ & $(+) 0.19 * *$ & $(+) 0.15^{*}$ & $(+) 0.18^{*}$ \\
\hline \multicolumn{6}{|c|}{ Makro Gelişmeler Özelinde Değişkenler } \\
\hline Nüfus & $(+) 0.15$ & $(+) 0.15$ & $(+) 0.17$ & $(+) 0.08$ & $(+) 0.11$ \\
\hline Enf & $(-) 2.56 * * *$ & $(-) 2.76 * * *$ & $(-) 2.73 * * *$ & $(-) 2.57 * * *$ & $(-) 2.58 * * *$ \\
\hline Arge1 & - & $(+) 2.22 * *$ & - & - & - \\
\hline Arge2 & - & - & $(+) 2.02 *$ & - & - \\
\hline İöe & $(+) 0.55^{* * *}$ & $(+) 0.50 * * *$ & $(+) 0.49 * *$ & $(+) 0.51^{* *}$ & $(+) 0.53^{* *}$ \\
\hline İth & - & - & - & - & $(+) 0.54$ \\
\hline İhr & - & - & - & $(+) 1.36$ & - \\
\hline Kriz & $(-) 1.87$ & $(-) 1.75$ & $(-) 1.77$ & $(-1.75$ & $(-) 1.76$ \\
\hline Dyy & $(+) 0.98$ & $(+) 0.88$ & $(+) 0.88$ & $(+) 0.91$ & $(+) 0.92$ \\
\hline Trend & $(-) 0.67$ & $(-) 0.65$ & $(-) 0.65$ & $(-) 0.66$ & $(-) 0.65$ \\
\hline Sabit & $(+) 0.00 * *$ & $(+) 0.00 * *$ & $(+) 0.00 * *$ & $(+) 0.00 * * *$ & $(+) 0.00 * * *$ \\
\hline Gözlem sayısı & 170 & 170 & 170 & 170 & 170 \\
\hline Log_like & -51.00 & -35.69 & -34.67 & -32.45 & -32.34 \\
\hline
\end{tabular}

Kaynak: Yazarlar tarafından oluşturulmuştur.

$*, * *, * * *$ sırasıyla $\% 10, \% 5, \% 1$ anlamlılık düzeyini göstermektedir.

Tablo 2'de de görüldüğü gibi, düşük teknolojiye sahip imalat sanayi sektöründe emek verimliliği, beklentilerle uyumlu olarak anlamlıdır. Çünkü düşük teknolojili sektörlerin emek yoğun sektörler olduğu bilinmektedir. Bu çerçevede, emek verimliliğinde görülen bir birimlik artış sonucunda, firmaların \%1 olasılıkla piyasaya giriş kararı alması beklenmektedir. Piyasada yoğunlaşmanın artmasıyla da firmaların piyasaya giriş için motivasyonlarında düşüş beklenmektedir. 
Çünkü artan yoğunlaşma, azalan rekabet ve azalan kar beklentisi oluşturacaktır. Üretimde meydana gelen artışlar ise düşük olasılıklarla da olsa firmaları piyasaya girme konusunda teşvik etmektedir. Makro iktisadi gelişmeler özelinde ise en önemli piyasaya giriş belirleyicisi, istikrar göstergesi olarak kabul edilen enflasyondur. Beklentilerle uyumlu olarak enflasyonda artış beklentisi, firmaları piyasaya girmekten vazgeçirmektedir. Benzer biçimde özel sektör ve kamu sektöründen sağlanan araştırma ve geliştirme harcamaları da firmalar için önemli bulunmaktadır. Bu desteklerin, firmaların teknoloji geliştirebilmeleri bakımından önemli bir fon kaynağı olacağı düşünülmektedir. Bu tür harcamalarda meydana gelen artışlar, piyasaya girişi olumlu yönde etkilemektedir. Bununla birlikte hukuk kurallarının işlerliğinin bir göstergesi olarak kabul edilebilen iktisadi özgürlük endeksi, düşük teknolojili imalat sanayi sektörlerinde de dikkate alınmaktadır. İktisadi özgürlük endeksinde yaşanan bir birimlik olumlu gelişmenin, yaklaşık $\% 0,5$ olasılık düzeyinde firmaların piyasaya giriş kararını etkilemesi beklenmektedir. Bununla birlikte sonuçlar, firmaların piyasaya giriş kararlarında, ticaretteki gelişmelerin, doğrudan yabancı yatırımların ve küresel finans krizinin dikkate alınmamış olduğunu ortaya koymaktadır.

Tablo 3: Yüksek Teknolojili Imalat Sanayisinde Piyasaya Girişin Belirleyicileri

\begin{tabular}{|c|c|c|c|c|c|}
\hline \multirow[b]{2}{*}{$\begin{array}{c}\text { Değişkenler için } \\
\text { gecikmeli değerler }\end{array}$} & \multicolumn{5}{|c|}{ Lojistik Regresyon Sonuçları-Bağımlı Değişken: Firmalaşma (kukla değişken) } \\
\hline & Model 1 & Model 2 & Model 3 & Model 4 & Model 5 \\
\hline \multicolumn{6}{|c|}{ Firma ve Sektör Özelinde Değişkenler } \\
\hline $\mathbf{W}_{1}$ & $(+) 0.95$ & $(+) 0.92 *$ & $(+) 0.91^{*}$ & $(+) 0.78^{*}$ & $(+) 0.80^{*}$ \\
\hline Kar & $(-) 1.12$ & $(-) 1.08$ & $(-) 1.12$ & $(-) 1.23$ & $(-) 1.21$ \\
\hline Verimlilik & $(+) 0.32$ & $(+) 0.42$ & $(+) 0.40$ & $(+) 0.38$ & $(+) 0.38$ \\
\hline Yoğunlaşma & $(-) 0.14^{* *}$ & $(-) 0.21 * *$ & $(-) 0.18^{* *}$ & $(-) 0.18^{*}$ & $(-) 0.19 *$ \\
\hline Büyüme & $(-) 0.25$ & $(-) 0.23$ & $(-) 0.24$ & $(-) 0.28$ & $(-) 0.28$ \\
\hline \multicolumn{6}{|c|}{ Makro Gelişmeler Özelinde Değişkenler } \\
\hline Nüfus & $(+) 0.08 * * *$ & $(+) 0.10 * *$ & $(+) 0.10^{* * *}$ & $(+) 0.09 * *$ & $(+) 0.08 * *$ \\
\hline Enf & $(-) 2.77 * * *$ & $(-) 2.98 * * *$ & $(-) 2.98 * * *$ & $(-) 2.67^{* *}$ & $(-) 2.69 * *$ \\
\hline Arge1 & - & $(+) 3.78 * *$ & - & - & - \\
\hline Arge2 & - & - & $(+) 3.56 * *$ & - & - \\
\hline İöe & $(+) 1.96 * * *$ & $(+) 2.05 * * *$ & $(+) 2.09 * * *$ & $(+) 2.18^{* * *}$ & $(+) 2.15^{* * *}$ \\
\hline İth & - & - & - & - & $(+) 0.77^{* *}$ \\
\hline îhr & - & - & - & $(+) 0.98 * *$ & - \\
\hline Kriz & $(-) 2.02 * * *$ & $(-) 1.98 * * *$ & $(-) 1.96 * * *$ & $(-) 2.08 * *$ & $(-) 2.07 * *$ \\
\hline Dyy & $(+) 3.25^{* * *}$ & $(+) 3.11^{* * *}$ & $(+) 3.12 * * *$ & $(+) 3.22 * *$ & $(+) 3.18^{* *}$ \\
\hline Trend & $(+) 0.98$ & $(+) 0.85$ & $(+) 0.87$ & $(+) 0.99$ & $(+) 1.00$ \\
\hline Sabit & $(+) 0.00$ & $(+) 0.00$ & $(+) 0.00$ & $(+) 0.00$ & $(+) 0.00$ \\
\hline Gözlem sayısı & 77 & 77 & 77 & 77 & 77 \\
\hline Log_like & -55.23 & -41.44 & -41.20 & -41.29 & -41.27 \\
\hline
\end{tabular}

Kaynak: Yazarlar tarafından oluşturulmuştur.

$*, * *,{ }^{* * *}$ sırasıyla $\% 10, \% 5, \% 1$ anlamlılık düzeyini göstermektedir. 
Tablo 3, yüksek teknolojili imalat sanayisi için piyasaya girişin belirleyicilerini ortaya koymaktadır. Bu çerçevede yoğunlaşma, enflasyon, iktisadi özgürlük endeksi, özel sektör ve kamu sektörü araştırma ve geliştirme harcamaları değişkenleri, düşük teknolojili imalat sanayisine benzer olarak yüksek teknolojili imalat sanayisi için de yakın sonuçlar ortaya koymaktadır. Bu durum, yüksek teknolojili imalat sanayisinde de yoğunlaşmanın itici güç olduğunu, enflasyonun istenmediğini, iktisadi özgürlük endeksine çok dikkat edildiğini ve özel sektör ve kamu sektörü araştırma ve geliştirme harcamalarının çekici etki yarattığını göstermektedir. Bununla birlikte, ar-ge harcamalarında görülen artışlar, ileri teknoloji içeren imalat sanayisinde firmalara piyasaya giriş konusunda daha yüksek motivasyon sağlamaktadır. Bu durum sürekli ar-ge geliştirmesi beklenen bu sektörlerde, ar-ge desteğinin önemini ortaya koymaktadır. Benzer bir biçimde iktisadi özgürlük endeksi ile temsil edilen hukuk kurallarının etkin çalışması sonucunda firma girişlerinde yaklaşık \%2 olasılı̆̆ında artış beklenmektedir. Diğer taraftan yoğunlaşma, yüksek teknolojili sektörlere girişte firmalar için olumsuz etki yaratsa da bu etki çok düşük düzeylerde gerçekleşmektedir. Düşük rekabet, yüksek teknolojili firmalarda çekingenlik yaratmamaktadır. Diğer taraftan düşük teknolojili imalat sanayisinden farklı olarak yüksek teknolojiye sahip imalat sanayisi için firmaların; personel maliyetlerine, nüfustaki artışa, sektöre gelen doğrudan yabancı yatırımlara, küresel finans krizine, ticaret rakamlarına göre piyasaya girme kararı aldıkları anlaşılmaktadır. Burada beklentilerin aksine personel maliyetlerinin, piyasaya girme kararında pozitif etkisi tespit edilmektedir. Personel maliyetleri, bilgi yoğun işgücüne ait maliyetleri göstermektedir. Bu sektörde çalışan bilgi yoğun işgücü için artan maliyetlerde, bilgi yoğun işgücüne ulaşmanın mümkün olduğunun bir göstergesi olarak kabul edilebilir. Bu tür işgücüne ulaşmanın mümkün olması da firmaların bu sınıf sektörlere girmesi yönünde çekici güç oluşturabilmektedir. Diğer taraftan beklentilerle uyumlu olarak doğrudan yabancı yatırımların ve dış ticaret hacminde genişlemenin çok yüksek olasılıklar ile piyasaya giriş için motivasyon yarattığı görülmektedir. Örneğin doğrudan yabancı yatırımlarda meydana gelen bir birim artış karşısında firma girişlerinin gerçekleşme olasılığının yaklaşık olarak \%3 artacağı beklenmektedir.

\section{Genel Değerlendirme}

Tüm dünyada olduğu gibi Türkiye'de de imalat sanayii başta olmak üzere sanayi sektörü, büyümenin önemli bir gücü olarak kabul edilmektedir. Çünkü gelişen imalat sanayi ile üretimin artması ve dolayısıyla ekonominin büyümesi beklenmektedir. Bununla birlikte, 2003 yılından sonra Türk imalat sanayisinde üretim ve katma değer artışlarının çok düşük düzeylerde gerçekleştiği ve imalat sanayine giren firma sayısının her geçen yıl azaldığı bilinmektedir. Bu durum, firmaların imalat sanayine giriş yapmalarında önemli olan etmenlerin ortaya koyulmasını gerekli görmektedir. Bu nedenle en başta firmalar, piyasaya giriş kararı almadan önce diğer firmaları iyi analiz etmeli, mevcut piyasa koşullarını değerlendirebilmeli ve makro iktisadi gelişmeleri takip etmelidirler. Diğer taraftan, politika yapıcılar ve uygulayıcılar tarafından da firmaların piyasaya girişini motive eden piyasa ve makro iktisadi koşullar oluşturulmalıdır.

Bununla birlikte tüm gelişmeleri dikkate alan modellerin oluşturulması ve piyasa analizlerinin yapılması firmalar ve etkin çalışan piyasaların oluşturulabilmesi için çok önemlidir. Buradan hareketle çalışmamızda, ekonometrik modeller yardımıyla farklı teknoloji düzeylerinde bulunan firmaların piyasaya giriş kararlarında hangi faktörlerin rol oynadığı ortaya koyulmaktadır. Bu çerçevede çalışmanın ana bulguları Tablo 4'te özetlemektedir. Tabloda da görüldüğü gibi düşük teknolojili imalat sanayine yeni bir firmanın giriş yapmasında; verimlilik, yoğunlaşma, iktisadi büyüme, iktisadi özgürlük endeksi, enflasyon, özel sektör ve kamu sektörü araştırma ve geliştirme harcamalarına ilişkin değişkenlerinin temel belirleyiciler oldukları ortaya çıkmıştır. Yüksek 
teknolojili imalat sanayinde ise firmaların daha çok makro iktisadi gelişmelerden etkilendikleri görülmüştür. Bu çerçevede, yüksek teknolojili imalat sanayine girişte; personel maliyeti, yoğunlaşma, nüfus, enflasyon, özel sektör ve kamu sektörü araştırma ve geliştirme harcamaları, iktisadi özgürlük endeksi, doğrudan yabancı yatırımlar, küresel finans krizi ve dış ticaret işlemleri temel belirleyiciler olarak tahmin edilmiştir.

Tablo 4: Imalat Sanayinde Piyasaya Girişin Belirleyicileri

\begin{tabular}{cc}
\hline Düşük Teknolojili Sektörler & Yüksek Teknolojili Sektörler \\
\hline \hline Verimlilik & Personel Maliyeti \\
Yoğunlaşma & Yoğunlaşma \\
Büyüme & Nüfus \\
İktisadi Özgürlük Endeksi & Enflasyon \\
Enflasyon & Arge (devlet ve özel sektör) \\
Arge (devlet ve özel sektör) & İktisadi Özgürlük Endeksi \\
& İmalat Sanayi Doğrudan Yabancı Yatırımlar \\
& Kriz \\
& Dış Ticaret Eğilimi
\end{tabular}

Burada dikkat çeken nokta, imalat sanayisinde karlılık değişkeninin firmalar için motivasyon kaynağı olmamasıdır. Bu durum, firmaların asıl amacının kar elde etmek olmasından dolayı karlılığın mutlak olacağını beklemelerinden kaynaklanmaktadır. Diğer taraftan, teknoloji sınıflamasına bakmaksızın yoğunlaşmanın, enflasyonun, iktisadi özgürlük endeksinin ve sektöre aktarılan ar-ge harcamalarının firmaların motivasyonlarına olumlu etki yarattıkları görülmektedir. Bu durum her koşulda rekabetçi piyasaların tercih edildiğini, makroekonomik istikrarın güven verdiğini, belirsizliğin ve yüksek maliyetin istenmediğini, hukuk kurallarının sorunsuz çalışmasına önem verildiğini, adaletli ve demokratik bir ülke yapısı istenildiğini, firmalara yönelik teşviklerin de her zaman esas olduğunu göstermektedir. Illaveten, yüksek teknolojili firmaların sayısının artması için incelenen diğer etmenler doğrudan yabancı yatırımlar ve dış ticaret hacmidir. Bu çerçevede doğrudan yabancı yatırımların ülkeye gelmesine olanak verecek istikrarlı ve güvenilir bir ortamın oluşturulması da beklenmektedir.

Özetle, elde edilen sonuçlar, makro gelişmelere daha fazla önem verildiğini göstermektedir. Bu çerçevede firmaların tek başlarına sahip olamayacakları destekler için teşvik sisteminin etkin çalıştırılması ve küresel destek anlamında da doğrudan yabancı yatırımların ülke içerisine çekilmesi gerekmektedir. Bir başka ifadeyle, yeri geldiğinde sektörden ziyade firma odaklı desteklerin verilmesi, KOBi ve TÜBITAK desteklerinin de içeriklerinde bazı düzenlemeler yapılması önerilmektedir. Diğer taraftan rekabet kurulu tarafından piyasaya giriş ve çıkış engelleri tekrardan değerlendirilmelidir. İşgücü bakımında ise nitelikli işgücüne sahip olmak adına eğitime önem verilmelidir. Sanayi 4.0`ın getirdiği yeni iş alanlarına yönelik eğitim reformları gerçekleştirilmelidir.

Türkiye Sanayi Stratejisi Belgesi ve Eylem Planı'nda (2015) da teknoloji yoğun sektörlere ağırlık verilmesinin gerekliliği vurgulanmıştır. Bu çerçevede sektör içerisindeki teknoloji yoğun firmalara önem verilmeli, bu nedenle de piyasa ve makroekonomik koşullar uygun hale getirilmelidir. Diğer taraftan, teknoloji yoğun sektörlere önem verilirken, rekabet avantajına sahip olduğumuz emek yoğun sektörlere yönelik çalışmalar da devam etmeli, bu sektörde yer almak isteyen firmalar için de beklentilere uygun koşullar yaratılmalı, gerekli destekler sağlanmalıdır. 


\section{Eskişehir Osmangazi Üniversitesi iiBF Dergisi}

\section{Kaynaklar}

Adams, Robert; Amel, Dean (2016), "The Effects of Past Entry, Market Consolidation, and Expansion by Incumbents on the Probability of Entry in Banking”, Review of Industrial Organization, 48(1): 95-118.

Akay, E. Ç. (2015), "Panel Nitel Tercih Modelleri”, (Ed.Selahattin Güriş), Stata ile Panel Veri Modelleri, İstanbul: Der Yayınları: 175-192.

Arıkan, Başak (2015), Türk Bankacılığında Inovasyon ve Kreatif Bankacılık, İstanbul: İstanbul Ticaret Üniversitesi Sosyal Bilimler Enstitüsü.

Amel, Dean; Liang, Nellie (1997), "Determinants of Entry and Profits in Local Banking", Review of Industrial Organization, 12(1): 59-78.

Austin, John; Rosenbaum, David (1990), "The Determinants of Entry and Exit Rates into U.S. Manufacturing Industries", Review of Industrial Organization, 5(2): 211-223.

Avery, Robert; Bostic, Raphael; Calem, Paul; Canner, Glenn (1999), "Consolidation and Bank Branching Patterns", Journal of Banking \& Finance, 23(2-4): 497-532.

Bain, Joe (1951), "Relation of Profit Rate to Industry Concentration: American Manufacturing, 1936-1940", The Quarterly Journal of Economics, 65(3): 293-324.

Bilim Sanayi Teknoloji Bakanlı̆̆ı, Türkiye Sanayi Stratejisi Belgesi (2015-2018), 2015.

Berger, Allen; Bonime, Seth; Goldberg, Lawrence; White, Lawrence (2004), "The Dymanics of Market Entry: The Effects of Mergers and Acquisitions on De Novo Entry and Small Business Lending in the Banking Industry", Journal of Business, 77(4): 1-64.

Çetin, Tamer (2010), “iktisadi Etkinlik Üzerine Bir Deneme: X Etkinlik Yaklaşımı”, Doğuş Üniversitesi Dergisi, 11(2): 183198.

Pagnini, Marcello; Rossi, Paola; Vacca, Valerio; Burgstaller, Johann (2017), "Dynamics of Retail-Bank Branching Austria”, Economic Notes , 46(3): 527-554.

Cala, Carla Daniela (2018), "Sectoral and regional determinants of firm Dynamics in developing countries: evidence for low-, mediumand high-tech manufacturing in Argentina". CEPAL Review, 124: 121-141.

Doğan, Mesut (2013), "Türkiye'de Sanayileşme Sürecine Genel Bir Bakış”, Marmara Coğrafya Dergisi, 28: 211-231.

Gobbi, Giorgio; Lotti, Francesca (2004), "Entry Decisions and Adverse Selection: An Empirical Analysis of Local Credit Markets", Journal of Financial Services Research, 26(3): 225-244.

Genchev, Evgeni (2015), "Determinants of Entry and Exit Rates in Australian Industry", B\&M Publishing, San Francisco, California, USA, 45-57.

Günalp, Burak; Cilasun, Seyit Mümin (2006), "Determinants of Entry in Turkish Manufacturing Industries”, Small Business Economics, Springer, 27(2): 275-287.

İzgi, Berna Balcl; Dineri, Eda (2014), “Determinants of Market Entry: A Study on Turkish Manufacturing Industry (19962001 Period)", Folıa Oeconomıca, 6(309): 7-14.

Kaldor, Nichoas (1966), Causes of the Slow Rate of Growth of the United Kingdom An Inaugural Lecture. Cambridge: Cambridge University Press.

Kaya, Seçil; Üçdogruk, Yeşim (2002), "The dynamics of entry and exit in turkish manufacturing industry", ERC Working Papers 0202, ERC - Economic Research Center, Orta Doğu Teknik Üniversitesi.

Koç, Erdem; Kaya, Kadir; Şenel, Mahmut Can (2016), "Türkiye'de Sanayi Sektörü ve Temel Sanayi Göstergeleri - Sanayi Üretim Endeksi", Mühendis ve Makina, 57(682): 42-53.

Kozal, Erdölek Özge; Barbaros, R.Funda (2019), "The Future of Manufacturing Industry in the 21st Century: Industrial Robots", Berlin: Peter Lang GmbH.

McCombie, John (1982), "Economic growth, Kaldor's laws and the static-dynamic Verdoorn law paradox", Applied Economics, 14(3): 279-294.

Orr, Dale (1974), "The Determinants of Entry: A Sudy of the Canadian Manufacturing Industries", The Review of Economics and Statistics, MIT Press, 56(1): 58-66.

Öztürk, Nurettin; Karabıyık, Hörüşen (2007), “Rekabet Stratejileri ve Türk Bankacılık Sektöründe Uygulanabilecek Rekabet Stratejilerinin Değerlendirilmesi”, Süleyman Demirel Üniversitesi Iktisadi ve Idari Bilimler Fakültesi, 12(1): 229253. 
Öztürk, Evren Koç. (2010), Finansal Başarısızık Tahmin Metodlarının Karşılaştırılması ve Sektörel Bir Uygulama, İstanbul: Marmara Üniversitesi Sosyal Bilimler Enstitüsü.

Öztürk, Selcen; Kılıç, Dilek (2012), "Patterns and Determinants of Entry and Exit in Turkish Manufacturing Industries", International Journal of Arts and Commerce, 1(5): 107-118.

Öztürk, Selcen; Dietrich, Michael (2012), “Agglomeration, Firm Entry and Exit”, European Network on the Economics of the Firm (ENEF), Bologna, Italya, Acta Universitatis Lodziensis.

Rosenbaum, David (1993), "Profit, entry and changes in concentration", International Journal of Industrial Organization, 11(2): 185-203.

Roh, Yanghee (2018), Determinants of Firm Entry and Exit in Canada and the U.S, Yüksek Lisans tezi, Ottova Üniversitesi, 4457395.

Şahin, İbrahim Eren (2011), Şirket Birleşmelerinin Etkinlik Açısından Değerlendirilmesi ve Türk Bankacılık Sektöründe Bir Uygulama, Konya, Selçuk Üniversitesi Sosyal Bilimler Enstitüsü.

Turanlı, Selcen; Kılıç, Dilek (2009), “Determinants of Firm Exit in Turkish Manufacturing Industries”, 6th ENEF Meeting, Paris.

Yücebaş, Önder (2005), Şirket Birleşmeleri ve Türkiye Uygulaması, Ankara Üniversitesi Sosyal Bilimler Enstitüsü, 1-138.

https://www.heritage.org/, (Erişim: 24.10.2018)

https://www.mevzuat.gov.tr, (Erişim: 24.10.2018)

http://www.sbb.gov.tr/, (Erişim: 24.10.2018)

http://tuik.gov.tr/, (Erişim: 24.10.2018) 
Eskişehir Osmangazi Üniversitesi iiBF Dergisi

Ek 1: Değişkenlere ait Özet İstatistik Değerleri (Düşük Teknoloji)

\begin{tabular}{|c|c|c|c|c|}
\hline $\begin{array}{c}\text { Değişken } \\
\text { Türü } \\
\end{array}$ & Ortalama & Standart Sapma & $\begin{array}{c}\text { Minimum } \\
\text { Değer }\end{array}$ & $\begin{array}{c}\text { Maksimum } \\
\text { Değer }\end{array}$ \\
\hline $\mathbf{W}_{1}$ & 2.238 .416 .022 & 2.485.128.194 & 85.213 .943 & 12.839 .993 .745 \\
\hline Kar Oranı & 0.13 & 0.04 & 0.02 & 0.23 \\
\hline Verimlilik & 73.057 & 198.630 & 3.065 & 2.268 .163 \\
\hline Yoğunlaşma & 0.59 & 0.08 & 0.38 & 0.73 \\
\hline Büyüme & 0.94 & 2.09 & -0.76 & 7.69 \\
\hline Nüfus & 73713 & 2667 & 70231 & 78741 \\
\hline Enf & 9.06 & 3.00 & 6.2 & 18.4 \\
\hline Arge1 & 94221389 & 75952568 & 8106934 & 293832963 \\
\hline Arge2 & 35443397 & 28433671 & 3543005 & 97065049 \\
\hline İ̈̈e & 59 & 4.8 & 51 & 65 \\
\hline ìth & 176931 & 57742 & 69300 & 251700 \\
\hline inhr & 112723 & 35201 & 47300 & 157600 \\
\hline Dyy & 2361 & 1538 & 389 & 4652 \\
\hline
\end{tabular}

Kaynak: Yazarlar tarafından oluşturulmuştur.

Ek 2: Değişkenlere ait Özet Istatistik Değerleri (Yüksek Teknoloji)

\begin{tabular}{ccccc}
\hline $\begin{array}{c}\text { Değişken } \\
\text { Türü }\end{array}$ & Ortalama & Standart Sapma & $\begin{array}{c}\text { Minimum } \\
\text { Değer }\end{array}$ & $\begin{array}{c}\text { Maksimum } \\
\text { Değer }\end{array}$ \\
\hline $\mathbf{W}_{\mathbf{1}}$ & 2.251 .829 .561 & 1.715 .276 .657 & 341.767 .431 & 8.947 .971 .237 \\
\hline Kar Oranı & 0.13 & 0.03 & 0.06 & 0.23 \\
\hline Verimlilik & 47.307 & 37.735 & 5.277 & 230.109 \\
\hline Yoğunlaşma & 0.66 & 0.06 & 0.54 & 0.71 \\
\hline \hline Büyüme & 0.85 & 1.88 & -0.75 & 7.66 \\
\hline \hline Nüfus & 73.713 & 2.667 & 70.231 & 18.4 \\
\hline \hline Enf & 9.06 & 3.00 & 6.2 & 293.832 .963 \\
\hline \hline Arge1 & 94.221 .389 & 75.952 .568 & 8.106 .934 & 97065049 \\
\hline \hline Arge2 & 35443397 & 28433671 & 3543005 & 65 \\
\hline \hline Ïöe & 59 & 4.8 & 51 & 251.700 \\
\hline \hline İth & 176.931 & 57.742 & 69.300 & 157.600 \\
\hline \hline İhr & 112.723 & 35.201 & 47.300 & 4.652 \\
\hline \hline Dyy & 2.361 & 1.538 & 389 & 741 \\
\hline \hline
\end{tabular}

Kaynak: Yazarlar tarafından oluşturulmuştur. 


\section{Extended Summary}

\section{Determinants of Market Entry in High and Low Technology Sectors}

The industry sector is one of the most important strengths of growth. It is known that the most important subsector is the manufacturing industry with its contribution to both production and employment in the industrial sector. Because with the developing manufacturing industry, production is expected to increase and thus the economy will grow. For all these reasons, it is very important for the manufacturing industry to operate efficiently and to create effective policies to realize this aim. For effective policies, market analyzes must be made correctly. Within this framework, the most important analysis is the market structure analysis. In this way, the competitiveness level and competitiveness of the market can be determined and what should be done for an efficient market can be revealed. One of the most important issues in competition analysis is entry to and exit from the market.

In Turkey, the export-led growth was started in 1980, the industrial sector experienced with the onset of globalization and financial liberalization has become more important, the production level has increased with each passing day. After 1990, there were three important turning points for the industry sector. The first is the 2001 crisis and the other is the global financial crisis that started in 2008 and continued in 2009. Because, as a result of the global financial crisis in 2008, and especially the national crisis experienced in 2001, the industry sector production values were negatively affected. The concept of industry 4.0, which appeared in Germany in 2011, also gave a different dimension to the Turkish industry sector. With this development, the concept of technology has gained importance for the sector, sectors have started to be evaluated according to technology intensities and technology intensive sectors have come to the fore.

When assessed by technology intensity, it is seen that, production in low-tech manufacturing industry has been increasing while added value is increasing. However, it was not preferred to open a new business in the sector. This led to an idea that productivity in the low-tech manufacturing industry tends to increase. Despite this, the sector did not provide attractiveness for new firms. On the other hand, both production and added value have increased in the hightech manufacturing industry. However, the tendency to open new firms in the high-tech manufacturing industry has also decreased. These developments required detailed analysis of the manufacturing industry. Because of the decreasing attraction of the manufacturing industry with the increase in production and added value at low rates, it is an issue that needs to be examined in terms of competition policies.

In this study, the determinants of market entry in the Turkish manufacturing industry for 2003-2015 are analyzed with the logistic regression model, focusing on the distinction between low and high technology sectors. Because, in line with the developments after 2001, it is seen that the determinants for entering the Turkish manufacturing industry are not analyzed. However, it is obvious that there will be no single and common determinants in sectors with technological differences in market entry analysis. For this reason, the study focuses on the distinction between high and low technology sectors and the main determinants of entry into the market separately for each of the high and low technology sectors are presented for after 2003. In the models created for the analysis, variables are used specific for firm, sector and macro developments. In the analyzes made, the main determinants of entering the market in the low-tech manufacturing industry are; productivity, market concentration, economic growth, economic freedom index, inflation, private and public sector research and development expenditures. In addition to this, personnel cost, market concentration, population, inflation, private and public sector research and development expenditures, foreign direct investments, global financial crisis and foreign trade transactions stand out as the determinants of market entry in the hightech manufacturing industry.

The results obtained show that firms with different technology levels are affected by different variables when entering the market. On the other hand, macroeconomic developments are seen to be more effective in firms' decisions to enter the industry than firms and market-specific developments. It is noteworthy that especially technology intensive firms are seriously affected by macroeconomic developments. In this context, the incentive system should be run effectively and foreign direct investments should be drawn into the country in order to support the firms that cannot create these capabilities alone. On the other hand, it is recommended to provide firm-oriented supports and to make some adjustments in the contents of Small and Medium Enterprises and TUBITAK supports. The entry and exit barriers to the market should also be re-evaluated by the Competition Authority. In terms of laborforce, importance should be given to education in order to have a qualified laborforce. Education reforms should be carried out for new business areas brought by the Industry 4.0. While giving importance to technology-intensive sectors, projects for laborintensive sectors, where we have a competitive advantage, should also be continued, and suitable conditions should be created in accordance with the expectations of the firms that want to take part in this sector and necessary support should be provided. 
Eskişehir Osmangazi Üniversitesi iiBF Dergisi 